Artigo Original

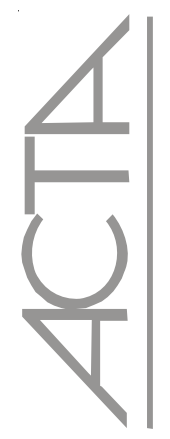

\title{
Mães de recém-nascidos hospitalizados: em/entre círculos no processo de amamentação*
}

\author{
Mothers of newborns born hospitalized babies: within/between circles in the breastfeeding process
}

Madres de recién nacidos hospitalizados: trayectoria en/entre círculos en el proceso de amamantamiento

Kleyde Ventura de Souza ${ }^{1}$, Renato Rissato Tesin ${ }^{2}$, Valdecyr Herdy Alves ${ }^{3}$

\begin{abstract}
RESUMO
Objetivo: Descrever o processo de amamentação de mães de recém-nascidos (RN) hospitalizados em uma Unidade Neonatal. Métodos: Estudo de abordagem qualitativa, realizado em uma maternidade situada na região central de Curitiba/PR, no período de abril a maio de 2007. Dez mulheres/mães de recém nascidos hospitalizados foram ouvidas. Os dados foram coletados por meio de entrevistas e submetidos à análise de conteúdo. Resultados: Identificou-se a seguinte unidade temática: o processo de amamentação de mulheres/mães de RN hospitalizados e as trajetórias em/entre os círculos, vicioso e virtuoso. Os elementos do "círculo vicioso" apontaram para aspectos ligados à assistência/ações de saúde; enquanto os elementos do "círculo virtuoso" relacionaram-se ao fortalecimento do papel da mulher, à importância e valorização de seu contexto e rede social. Conclusão: Considerando as várias dimensões que constituem o processo de amamentação, configura-se urgente a incorporação de práticas que reforcem o princípio e os sentidos da integralidade no cuidado à saúde.

Descritores: Amamentação; Relação mãe e filho; Recém-nascido; Equipe de cuidados de saúde
\end{abstract}

\begin{abstract}
Objective: To describe the process of breastfeeding of mothers with newborns (NB) hospitalized in a neonatal unit. Methods: This is a qualitative approach study, conducted in a maternity hospital located in the central region of Curitiba/PR, from April to May 2007. Were interviewed ten mothers of infants hospitalized. Data were collected through interviews and subjected to content analysis. Results: Was identified the following thematic unit: the process of breastfeeding of mothers with infants hospitalized and the paths of vicious and virtuous circles. The elements of the "vicious circle" were related to attendance/health actions; the elements of the "virtuous circle" were related to strengthening the role of women, importance and appreciation of context and, social network. Conclusion: Considering the various dimensions that constitute the process of breastfeeding, it is very urgent the incorporation of practices that reinforce the principle and the meaning of integral healthcare.
\end{abstract}

Keywords: Breast feeding; Mother and child relationship; Recent newborn; Patient care team

\section{RESUMEN}

Objetivo: Describir el proceso de amamantamiento de madres de recién nacidos ( $\mathrm{RN}$ ) hospitalizados en una Unidad Neonatal. Métodos: Se trata de un estudio de abordaje cualitativo, realizado en una maternidad situada en la región central de Curitiba/PR, en el período de abril a mayo de 2007. Se entrevistaron diez madres de recién nacidos hospitalizados. Los datos fueron recolectados por medio de entrevistas y sometidos al análisis de contenido. Resultados: Se identificó la siguiente unidad temática: el proceso de amamantamiento de madres de RN hospitalizados y las trayectorias en/entre círculos viciosos y virtuosos. Los elementos del "círculo vicioso" apuntaron aspectos relacionados a la asistencia/ acciones de salud; en cuanto que los elementos del "círculo virtuoso" se relacionaron al fortalecimiento del papel de la mujer, a la importancia y valorización de su contexto y a la red social. Conclusión: Considerando las varias dimensiones que constituyen el proceso de amamantamiento, es muy urgente la incorporación de prácticas que refuercen el principio y el sentido de la integralidad en el cuidado a la salud.

Descriptores: Amamantamiento; Relación madre e hijo; Recién nacido; Grupo de atención al paciente

* Este trabalho é parte da pesquisa intitulada: Quero/Posso/Devo Amamentar: a visão de mães de RN de risco, vinculada ao Grupo de Pesquisa: "Articulando Processos de Educação, Cuidado e Gerenciamento em Enfermagem - GECEG, do Curso de Enfermagem da Pontifícia Universidade Católica - PUCPR Curitiba (PR), Brasil.

${ }^{1}$ Doutora em Enfermagem. Professora Adjunto do Departamento Materno Infantil e Saúde Pública, da Escola de Enfermagem da Universidade Federal de Minas Gerias - UFMG - Belo Horizonte (MG), Brasil.

${ }^{2}$ Enfermeiro pela Pontifícia Universidade Católica - PUCPR - Curitiba (PR), Brasil.

${ }^{3}$ Doutor em Enfermagem. Professor Adjunto III do Departamento Materno-Infantil e Psiquiátrico da Escola de Enfermagem Aurora de Afonso Costa da Universidade Federal Fluminense - UFF - Rio de Janeiro (RJ), Brasil. 


\section{INTRODUÇÃO}

O leite humano é uma substância viva, de alta qualidade, grande complexidade biológica e forte ação protetora e imunomoduladora. $\mathrm{O}$ alimento é reconhecido como proteção natural contra alergias e infecções, além de estimular o desenvolvimento adequado do sistema imunológico do bebê $\hat{e}^{(1)}$. A superioridade do leite humano, quando comparada a outros tipos de alimentos, deve-se a fatores como: composição química e biodisponibilidade de nutrientes adequados; presença de fatores de proteção contra infecções e ausência de componentes alergênicos. Outros benefícios incluem a formação do vínculo entre mãe e filho e ausência de gastos com alimentação durante o período de aleitamento materno exclusivo (AME) $)^{(2)}$.

Os benefícios do leite materno têm sido ressaltados na literatura científica, também, para bebês prematuros ${ }^{(3)}$ que demandam cuidados especiais e atendimento hospitalar especializado em unidades neonatais ${ }^{(4)}$.

Nessas unidades, observa-se a baixa incidência de êxito na prática da amamentação $0^{(3)}$, que pode ser atribuída à separação por tempo prolongado entre a mãe e seu bebê; o estresse, a insegurança e a ansiedade da mãe; a imaturidade fisiológica e neurológica do recém-nascido; a dificuldade dos profissionais de saúde no apoio às mães para o estabelecimento do vínculo entre elas e seus filhos e, finalmente, as rotinas dos serviços de saúde ${ }^{(2)}$, que ainda não incorporaram em suas práticas o manejo clínico do aleitamento materno, visando à lactação e à amamentação bem-sucedidas.

Considerando-se os benefícios do aleitamento materno, particularmente para esses bebês, depreende-se que todos os esforços devem ser feitos visando ao apoio permanente às suas mães ${ }^{(3)}$, cujos possíveis problemas habituais podem ser potencializados por sentimentos de fracasso, culpa e tristeza frequentemente observados, em consequência do impacto do parto prematuro ou da separação precoce decorrente da necessidade do recémnascido(RN) de cuidados intensivos ${ }^{(5)}$.

No contexto das instituições de saúde, persistem as ações verticais, baseadas em regras normatizadoras da amamentação, instituídas na década de 1990 para reduzir a morbidade e mortalidade infantil( ${ }^{(6)}$. A partir de então, ganham visibilidade as ações de promoção, proteção e apoio à amamentação. Surgem correntes teóricas como a do modo valorativo do ato da amamentação, que incluem valores estéticos, afetivos e sociais. Desse ponto de vista, a mulher diante de suas incertezas e dificuldades precisa ser ouvida para melhor ser ajudada ${ }^{(7)}$.

Delineou-se, assim, como objeto deste estudo, a visão que as mulheres, mães de RN hospitalizados em uma Unidade Neonatal, têm de seu processo de amamentação. Definido o objeto, elaborou-se a seguinte questão norteadora: como se estabeleceu o processo de amamentação dessas mulheres? Para responder à questão, definiu-se, como objetivo descrever o processo de amamentação de mães de RN hospitalizados em uma Unidade Neonatal.

\section{MÉTODOS}

O estudo aqui descrito é de caráter exploratório, descritivo com abordagem foi a qualitativa ${ }^{(8)}$. O trabalho foi realizado na Unidade Neonatal de uma instituição filantrópica, com mais de $95 \%$ de seus atendimentos destinados a usuárias do Sistema Único de Saúde (SUS) de Curitiba e Região Metropolitana. Localizado em Curitiba, o serviço é responsável pelo maior número de nascimentos no Estado do Paraná (aproximadamente, 600 por mês). A unidade dispõe de 13 leitos na unidade neonatal e suas instalações acolhem, em média, 55 internações mensais.

Todas as mulheres com filhos internados nesse serviço, no período de 30 de abril a 30 maio de 2007, foram convidadas a participar do estudo, das quais dez foram entrevistadas. A participação na pesquisa levou em conta os seguintes critérios de inclusão: mães de $\mathrm{RN}$ internados na unidade neonatal; estar amamentando ou ordenhando leite do próprio peito para seu filho; frequentar a unidade neonatal no mínimo três vezes por semana.

Adotou-se um roteiro semiestruturado destinado à identificação de variáveis que possibilitassem a descrição do perfil das participantes e a apreensão da visão dos sujeitos sobre o objeto de estudo.

As transcrições dos dados originaram o corpus do estudo, organizado com base em eixos temáticos previamente definidos, a saber: quero amamentar/devo amamentar/posso amamentar. Esses eixos foram constituídos por recortes das falas (afirmações) das participantes em torno da questão e submetidos à regra de pertinência. Isso permitiu a elaboração de uma unidade temática, a partir da análise de conteúdo ${ }^{(9)}$.

Em conformidade com a Resolução nº. 196/96 do Conselho Nacional de Saúde, o estudo foi aprovado pelo Comitê de Ética em Pesquisa da Pontifícia Universidade Católica do Paraná - CEP/PUCPR of. n 1619/07. Todas as participantes assinaram um Termo de Consentimento Livre e Esclarecido (TCLE).

\section{RESULTADOS}

A caracterização do público-alvo indicou idade entre 19 e 37 anos. A maioria completou o ensino fundamental e não tinha ocupação formal. A renda familiar variou de um a cinco salários mínimos, e as mães pesquisadas viviam em famílias do tipo nuclear.

Seis eram primíparas; seis tiveram partos normais e duas relataram complicações no parto. Desse grupo, seis deram à luz a bebês prematuros; nos demais casos os 
diagnósticos dos RN foram Síndrome do Desconforto Respiratório (SDR); em dois casos, baixo peso ao nascer e infecção. A experiência de ter amamentado foi referida por quatro mulheres, tendo em vista a situação de primiparidade das demais.

As entrevistadas informaram que apenas seu leite foi usado para alimentar o bebê. No momento da entrevista, seis já estavam mamando no peito, três eram alimentados por sonda orogástrica e uma amamentava seu bebê no seio e complementava as mamadas com auxílio de copinho. Não foi mencionado o uso de mamadeira ou similar.

As unidades de registro foram agrupadas por semelhança, dando origem a dois núcleos de sentidos antagônicos. O primeiro conjunto foi constituído por fatores, que formaram o circulo vicioso; e o segundo, indicou a concepção de um circulo virtuoso. Esses núcleos de sentido possibilitaram a elaboração da unidade temática: o processo de amamentação de mulheres/mães de RN hospitalizado - trajetórias em e entre círculos: vicioso e virtuoso, objeto de análise neste estudo.

\section{DISCUSSÃO}

Em foco: O processo de amamentação de mulheres/mães de RN hospitalizado - trajetórias em e entre círculos: vicioso e virtuoso.

A percepção das mulheres sobre os fatos e situações que marcaram seu processo de amamentação aproximouse da imagem de um círculo - uma superfície plana demarcada por uma circunferência e, nela, um ponto central $^{(10)}$. Também pôde ser associada à ideia de movimento, com alternativas de entrada e saída, admitindose, assim, possibilidades em uma lógica não hierarquizada ${ }^{(11)}$. A imagem de círculo foi associada à qualidade de apresentarse como vicioso ou como virtuoso.

O círculo vicioso originou-se do conjunto de circunstâncias relacionadas aos fatores que interferiram no início/estabelecimento da amamentação. Nele, agruparam-se os problemas ligados à ambiência hospitalar; assistência profissional; medo e insegurança decorrentes de dificuldades no manejo da amamentação e condição clínica da criança. Essa seqüência de fatos e acontecimentos configurou-se como obstáculos. No círculo virtuoso prevaleceram os fatores potencializadores do processo: o fortalecimento de sentimentos, como o poder e a magnitude da mulher em relação à amamentação; seu conhecimento e crença a respeito das vantagens do aleitamento materno e o apoio recebido por parte da equipe profissional e de sua família.

Já a "porta" de entrada do "círculo vicioso", referiu-se à ambiência hospitalar. A ambiência é definida como um conjunto de ações voltadas para o aparelhamento que inclui espaço físico e organização do espaço social, compreendendo as relações interpessoais, com vistas à atenção acolhedora, humana e resolutiva. Esse tipo de ambiência baseia-se em três eixos principais: a) possibilidade de reflexão do trabalhador de saúde sobre sua produção e processo de trabalho; b) confortabilidade - privacidade e individualidade dos trabalhadores, usuários e sua rede social; c) ferramenta do trabalho funcional - otimização de recursos; humanização, acolhimento e resolutividade ${ }^{(12)}$.

O eixo relacionado à confortabilidade foi o mais citado pelas mulheres, destacando-se a falta de conforto e privacidade: "a dificuldade de dar de mamar e o acesso de muitas outras pessoas, muita gente circulando... O banheiro épequeno, a gente tem medo de alguém abrir a porta e te pegar (sem roupa). Então, isso tira um pouco da privacidade... Falta também um pouco mais de conforto para gente na hora de dar de mamar (Mãe C)". "As dificuldade de estar num quarto com seis mães. É complicado, tanto para elas quanto para mim... porque o tumulto, é muito agito, muita gente no mesmo quarto, muita conversa (Mãe $\mathrm{H})$ ”.

Mães de RN internados em unidade neonatal enfrentam um grande impacto emocional e sentimentos de temor pela vida e saúde de seu filho. Muitas vezes, as mães não podem e/ou não conseguem cuidar e sobrevém a tristeza pela separação por um período indeterminado ${ }^{(13)}$. Para superar essas dificuldades, as mulheres devem ser encorajadas.

Recomenda-se a adoção de ações voltadas à (re)organização do espaço social hospitalar, que exige dos profissionais, modos inovadores de cuidar. Entre eles, incluímos a formação de grupos de apoio ${ }^{(14)}$ - com a participação efetiva das mães, que são protagonistas desse processo. Esta é a melhor maneira de estimular a solidariedade entre elas, em contraposição ao isolamento a que são submetidas.

A evolução da tecnologia observada em ambientes de assistência a bebês hospitalizados é inquestionável. No tipo de unidade hospitalar usada na pesquisa, são empregadas técnicas e procedimentos sofisticados e capazes de propiciar melhora na sobrevida dos RN. Por isso, ruídos, luminosidade intensa, procedimentos invasivos e dolorosos fazem parte da rotina de cuidados ${ }^{(15)}$.

Em ambientes como estes, a produção de cuidados em saúde deve ser articulada com atitudes e práticas de acolhimento, de modo que haja a conciliação entre o uso de tecnologias apropriadas, respeito ao paciente e aos aspectos culturais de sua família e rede social. Deve-se contemplar também a promoção de espaços e processos de trabalho favoráveis ${ }^{(16)}$.

Para pais e mães, esse ambiente é fonte de esperança e temor. De um lado, eles reconhecem que essas unidades disponibilizam recursos humanos, materiais e tecnológicos importantes para a manutenção da vida e aumento da chance de sobrevida de seus filhos. Nesse contexto, fundamenta-se a esperança. Por outro lado, os pais do $\mathrm{RN}$ sentem medo, porque reconhecem os riscos inerentes 
às situações críticas. Soma-se a isso o sentimento de frustração pela separação imposta em virtude da internação de seus bebês ${ }^{(15)}$.

Estudos recentes apontam as consequências imediatas e desfavoráveis na relação entre mãe e filho submetido à internação em unidades críticas. Propostas têm sido elaboradas. Uma delas é a abordagem do cuidado individualizado e centrado na familia, em contraposição ao atendimento clínico centrado no bebê e em sua evolução clínica. Quando as ações de promoção de bemestar e de saúde do RN em estado crítico dependem da figura materna - a amamentação é uma delas - é imprescindível que as percepções, os sentimentos e as crenças dessa mulher sejam reconhecidos. Estas impressões contribuem decisivamente nas orientações que nortearão as intervenções facilitadoras do cuidado individualizado do bebê $\hat{e}^{(17)}$.

Tema muito discutido por profissionais, gestores e formuladores de políticas públicas em saúde, o acolhimento ganhou visibilidade porque se tornou uma das diretrizes da Política Nacional de Humanização do SUS. A prática é entendida como a atitude de estar em relação com alguém. O que faz desse tipo de interação o que ele é consiste em reconhecer no outro o outro que lá está - respeitando sua individualidade e seu modo de sentir e viver. Só assim será possível desenvolver as potencialidades do indivíduo e dignificar a vida e seu próprio viver ${ }^{(18)}$.

A segunda "porta" de entrada do "círculo vicioso" descrito, relacionou-se à assistência profissional, com destaque para a dificuldade no acolhimento por parte dos profissionais. Foi possível apontar a pouca eficácia de ações do tipo orientação e apoio no manejo clínico em amamentação, particularmente, quando realizadas de forma verticalizada e impositiva.

No processo de amamentação, o apoio profissional consiste em fornecer orientações e aconselhar a mãe, de modo a prevenir complicações e transformar o ato de amamentar em uma experiência prazerosa ${ }^{(19)}$. Esse tipo de ação é imprescindível, sobretudo quando levamos em conta a situação em que se encontravam essas mulheres/mães.

Identificamos um número elevado de mulheres/mães que não foram esclarecidas sobre as dúvidas relacionadas ao estado de saúde dos filhos.

"falta de informação dos próprios funcionários, que não passam essa segurança pra gente..." (Mãe D). "A dificuldade que eu tive, foi entender bem o que minha filh a teve. Nos primeiros dias, foi falado uma coisa, depois outra... Ficou complicado pra mim (Mãe F).

A comunicação e a utilização de estratégias que favoreçam a interação entre a equipe de saúde e a família são componentes fundamentais do cuidado de qualidade e humanizado ${ }^{(20)}$. Frequentemente, o foco de atenção volta- se para o cuidado prestado ao $\mathrm{RN}$ e ao atendimento de suas necessidades. Isso acontece em virtude de seu estado crítico, mas também do modelo assistencial brasileiro tecnocrático e voltado à cura em detrimento do cuidado.

Muitas vezes, a equipe de saúde, agindo de forma automatizada, impessoal e mecanizada, assume, sem disso ter consciência, uma postura autoritária. Por isso, a comunicação com as mães/pais/familiares torna-se assimétrica e intangível. Por outro lado, a instrumentalização dos profissionais, isto é, a capacidade de utilizar conhecimentos e tecnologias de interação é de grande importância para a efetividade da promoção do cuidado dos bebês e do bem-estar de sua rede social ${ }^{(20)}$.

Notamos também que o cotidiano das instituições de atendimento à mulher, especialmente, o trabalho em saúde foi mecanizado. A frequência disso é a falta de sensibilidade dos profissionais que não valorizam a amamentação, como segurança alimentar do $\mathrm{RN}^{(21)}$. Amamentar o filho tem um significado tão importante, na saúde da mulher e do bebê, quanto a gestação, o parto, o nascimento ${ }^{(14)}$. E ganha relevância quando acontece em estados de adversidade.

A terceira "porta" de entrada desse círculo foi identificada como medo e insegurança decorrentes de dificuldades no manejo do aleitamento. O processo de amamentação é biologicamente determinado e sócicultural condicionado, baseado em ideias lógicas e determinantes das experiências vividas pelas mulheres/ mães. E o ato de amamentar pode ser compreendido como uma prática social, culturalmente construída e regulada pela sociedade, cujos resultados se apresentam e se refletem em condições concretas ${ }^{(21)}$.

A amamentação, prática inscrita em um universo moral, engendra a imagem de boa mãe. Por isso, o RN torna-se o foco da atenção também às mulheres. Seus corpos concretizam-se como corpo-função. Em caso de problemas, concebe-se que a mãe é culpada e responsável pelos possíveis prejuízos ao corpo do filho ${ }^{(22)}$.

Somente ações do tipo informação ou orientação não bastam, para que as mulheres superem as dificuldades $\mathrm{e}$ iniciem a amamentação. É preciso condições concretas, para que as mães e os bebês vivenciem esse processo de forma mais prazerosa possível e sintam-se motivadas a insistir diante dos obstáculos. Nesse sentido, reitera-se a premente incorporação do princípio da integralidade nas ações em saúde.

“... na verdade, eu fui (apoiada) por outras mães, que tinham muito mais experiência, que tinham dois ou três filhos. Perguntei e tirei todas as minhas dúvidas, inclusive, sobre os seios, o que acontece depois da amamentação..." (Mãe B). "O meu problema maior mesmo é quando a quantidade do meu leite, que é muito pouco... É que ela (sua filha) ainda não está fazendo a pega direito... Mas, eu, em casa, eu estimulo (a produção de leite). Mas, quando ela começar a sugar bem, talvez melhore a produção...” (Mãe J). 
A quarta de entrada se referiu à condição clinica do RN. Esse aspecto foi identificado como um importante obstáculo ao início/estabelecimento do processo de amamentação, tendo em vista o frágil estado de saúde, a imaturidade dos sistemas orgânicos, a possibilidade de complicações e a necessidade de adaptação do $\mathrm{RN}$ a sua nova realidade.

Bebês hospitalizados com: prematuridade, peso muito baixo, estados clínicos e cirúrgicos delicados - na maior parte das vezes se beneficiam da amamentação. Só em situações muito raras o leite materno é contraindicado. Mães de bebês com esse tipo de condição devem receber atenção e apoio de forma ainda mais contundente, uma vez que as incertezas, angústias e ansiedades oriundas da situação clínica de seus filhos colocam-nas em situação de fragilidade. Afinal de contas, são conflitos e desafios que emergem em um contexto marcado por "limites entre ser o 'corpo para o filho' e de ser o 'corpo para si ${ }^{(22.355-63)}$.

"... o que está dificultando éesse banho de luz que meu filho está tomando agora, ele tá internado pelo fato de estar com probleminha de saúde. Eu acho que tudo isso deixa meu filho muito desconfortável..." (Mãe C). "Eu não sei se vou conseguir voltar a trabalhar, porque fica dificil deixar ele (o bebê)..." (Mãe D).

Desse contexto conflituoso e desafiante, originaramse delineamentos que tangenciaram as "portas" de entrada do "círculo virtuoso", indicando possibilidades de hiatos e interseções. Nesse limiar - em e entre "círculos: vicioso e virtuoso" - foi possível identificar a primeira "porta" de entrada do "círculo virtuoso", que se relacionou ao fortalecimento de sentimentos, como poder e magnitude da mulher em relação à amamentação.

"amamentar é uma forma em relação à amamentação muito grande de carinho e emoção. É prazeroso! A partir do momento que você nota que está produzindo leite, que o nenê tem, assim, a facilidade de sugar é ótimo. Sensação melhor que essa, eu acho que não existe pra uma mãe..." (Mãe B). "Aumenta o laço de amor e carinho, que a mãe tem com o bebê, que já vem desde a gestação. Amamentando, eu acho que é melhor ainda. O bebê se sente mais seguro, mais tranquilo e vai ficar mais saudável com o leite da mãe..." (Mãe D).

A segunda "porta" de entrada foi o conhecimento e a crença da mulher a respeito das vantagens do aleitamento materno.

"eu quero muito amamentar, para ele crescer mais rápido, mais forte, ser mais rico em saúde. Eu posso (amamentar) também porque eu tenho esse leite e eu devo (amamentar) porque é a melhor coisa que eu sonhava na minha vida..." (Mãe E). "Meu leite vai ajudar meu bebê a ganhar peso. Sei isso porque a minha primeira filha ganhou peso rápido e não ficou doente. Dificilmente, ela fica
doente...”(Mãe A).

A terceira "porta" de entrada do "círculo virtuoso" relacionou-se ao apoio por parte da equipe profissional.

"Sim, tive (orientação) das enfermeiras; orientaram tudo a respeito do aleitamento, como devia fazer massagem para não empedrar o leite no seio... Como amamentar corretamente o bebê; segurá-lo para que ele não se afogar. Para que ele fique mais seguro, mame bastante, não lárgue o seio... Essas coisas bem especial. Eles alertaram bem (de forma) que eu aprendi bem. Meu filho está bem, estou me sentindo felizpor ele ter pego bem o seio...” (Mãe C).

Finalmente, a quarta "porta" de entrada referiu-se ao apoio da família:

"Tenho muito apoio de todos, hoje me sinto mais segura, pois tenho apoio do marid, e dos meus familiares. É o que eu precisava! $O$ amor que eles passaram pra mim, me faz ficar de pé, porque não é fácil gerar um bebê com problemas. Você (mãe) sempre tem que estar bem apoiada, volto para casa com o pessoal de bracos abertos..." (Mãe C).

Evidenciou-se uma dinâmica que reforça a situação/ condição de maternidade, como algo naturalizado e que se estende à prática da amamentação:

"Quero (amamentar), porque meu leite é suficiente para alimentálo..." (Mãe A). "A partir do momento que você nota que você está produzindo leite... Eu acho que não existe coisa melhor para uma mãe...” (Mãe B). “... é interessante pelo fato de, como já tinha dito, te dar prazer ver que ele (o filho) está crescendo...” (Mãe C). "Uma missão da gente (mãe), não tem como explicar...” (Mãe D). "Eu quero muito amamentar, para ele crescer mais rápido, mais forte, ser mais rico em saúde... Eu tenho esse leite; eu devo (amamentar), porque é o que eu sonhava na minha vida..." (Mãe E).

A mesma lógica norteou a prática dos profissionais da saúde. A ênfase no apoio oferecido voltou-se para o incentivo da produção do leite. Uma das mães chegou a mencionar que "como o médico disse, vai ser o remédio da criança...” (Mãe I). Demonstrou-se, assim, que a afirmação do desejo idealizado de amamentar encontra-se, subliminarmente, associada ao fato de dar o melhor de si para seu filho, com respaldo do discurso e das práticas de saúde, oficialmente instituídas ${ }^{(22)}$.

Os dois últimos componentes do "círculo virtuoso" - apoio dos profissionais de saúde e da família - foram expressivamente apontados pelas mulheres. Justifica-se, dessa maneira, a importância de fortalecer as práticas hospitalares. Elas (as práticas) devem voltar-se para a compreensão do contexto em que essas mulheres e sua rede social encontram-se ${ }^{(23)}$. 


\section{CONSIDERAÇÕES FINAIS}

Nessa pesquisa, buscamos descrever a visão de mulheres/mães de $\mathrm{RN}$ hospitalizados e seu processo de amamentação. Observamos trajetórias que nos deram a visibilidade necessária para delinear os fatores que dificultam ou potencializam a prática de amamentar o recém-nascido. Isso nos permitiu também circunscrevêlos em/entre "círculos: vicioso e virtuoso".

Os elementos ou "portas" de entrada do "círculo vicioso" - contido no processo vivenciado pelas mulheres deste estudo - indicaram que os aspectos ligados à assistência/ações de saúde foram preponderantes. Paralelamente, os elementos ou "portas" de entrada do "círculo virtuoso" relacionaram-se, fundamentalmente, ao fortalecimento do papel da mulher e da importância e valorização de seu contexto e de sua rede social. É urgente, assim, incorporar práticas que reforcem o princípio e os sentidos da integralidade no cuidado à saúde.

\section{REFERÊNCIAS}

1. Junqueira P. Amamentação, hábitos orais e mastigação: orientações, cuidados e dicas. 3 a. ed. Rio de Janeiro: Revinter; c2005. p. 9-10.

2. Giugliani ERJ. Amamentação exclusiva e sua promoção. In: Carvalho MRC, Tamez RN. Amamentação: bases científicas para a prática profissional. Rio de Janeiro: Guanabara Koogan; 2002. p. 12-24.

3. Nascimento MBR, Issler H. Aleitamento materno em prematuros: manejo clínico hospitalar. J Pediatr (Rio J). 2004;80(5 Supl):S163-72.

4. Bicalho-Mancini PG, Velásquez-Meléndez G. Aleitamento materno exclusivo na alta de recém-nascidos internados em berçário de alto risco e os fatores associados a essa prática. J Pediatr (Rio J). 2004;80(3):241-8.

5. Alfaya C, Schermann L. Sensibilidade e aleitamento materno em díades com recém-nascidos de risco. Estud Psicol (Natal). 2005;10(2):279-85

6. Monteiro JCS, Gomes FA, Nakano AMS. Percepção das mulheres acerca do contato precoce e da amamentação em sala de parto. Acta Paul Enferm. 2006;19(4):427-32.

7. Alves VH. O ato da amamentação: um valor em questão ou uma questão de valor? [tese]. Rio de Janeiro: Universidade Federal do Rio de Janeiro. Escola de Enfermagem Anna Nery; 2003.

8. LoBiondo-Wood G, Haber J. Pesquisa em enfermagem: métodos, avaliação crítica e utilização. 4a ed. Rio de Janeiro: Guanabara Koogan; 2001.

9. Bardin L. Análise de conteúdo. Lisboa: Edições 70; 2004.

10. Barison MB. Geométrica: desenho, geometria e arquitetura on-line. Disponível em: http://www.mat.uel.br/ geometrica. Acessado em 18 de agosto de 2008.

11. Cecílio LCO. Modelos tecno-assistenciais em saúde: da pirâmide ao círculo, uma possibilidade a ser explorada. Cad Saúde Pública = Rep Public Health. 1997;13(3):469-78.

12. Brasil. Ministério da Saúde. Secretaria Executiva. Núcleo Técnico da Política Nacional de Humanização. HumanizaSUS: Ambiência. Brasília: Ministério da Saúde; 2004.

13. Scochi CGS, Kokuday MLP, Riul MJS, Rossanez LSS, Fonseca LMM, Leite AM. Incentivando o vínculo mãe-filho em situação de prematuridade: as intervenções de enfermagem no Hospital das Clínicas de Ribeirão Preto. Rev
Considerando as várias dimensões que constituem a prática da amamentação - particularmente, em situações críticas para o bebê, à mulher e sua família - o caminho a ser tomado, por parte dos serviços/profissionais da saúde, é o da (re)inovação de atitudes e práticas que considerem: o contexto social e as possibilidades e limitações individuais das protagonistas - as mulheres/mães; a condição clínica do bebê. Deve-se levar em conta o conhecimento, a capacidade, as condições e modelos assistenciais dos profissionais, de maneira que a articulação saber-prática, permeada por relações afetivas e solidárias, ultrapasse o campo biológico. Nessa perspectiva, julgamos ser importante fortalecer as "portas" de entradas do "círculo virtuoso". Essas práticas devem ser necessariamente fortalecidas para desencadear outras ações sucessivas e na mesma dimensão.

Agradecimentos: pela coleta de dados a Antônio Costa; Kátia Domingos; Márcio Batista e Marcos Corde.

Latinoam Enferm. 2003;11(4):539-43.

14. Reichert APS, Lins RNP, Collet N. Humanização do cuidado da UTI neonatal. Rev Eletrônica Enferm. [internet] 2007 [citado 2008 Jun 20]; 9(1): [cerca de 14 p.]. Disponível em: http://www.fen.ufg.br/revista/v9/n1/v9n1a16.htm

15. Lamego DTC, Deslandes SF, Moreira MEL. Desafios para a humanização do cuidado em uma unidade de terapia intensiva neonatal cirúrgica. Ciênc Saúde Coletiva. 2005;10(3):669-75.

16. Rabelo MZS, Chaves EMC, Cardoso MVLML, Sherlock MSM. Sentimentos e expectativas das mães na alta hospitalar do recémnascido prematuro. Acta Paul Enferm. 2007;20(3):333-7.

17. Correia LL, Carvalho AEV, Linhares MBM. Conteúdos verbais expressos por mães de bebês prematuros com sintomas emocionais clínicos. Rev Latinoam Enferm. 2008;16(1):64-70.

18. Brasil. Ministério da Saúde. Secretaria de Atenção à Saúde. Núcleo Técnico da Política Nacional de Humanização. Acolhimento nas práticas de produção de saúde. Brasília: Ministério da Saúde; 2006.

19. Pamplona V. Aspectos psicológicos na lactação. In: Carvalho MR, Tamez RN. Amamentação: bases científicas para a prática profissional. Rio de Janeiro: Guanabara Koogan; 2002. p. 96-105.

20. Munhoz Gaíva MA, Scochi CGS. The communication between the team and parents at a neonatal intensive care unit of a university hospital. In: Proceedings of the 8 . Brazilian Nursing Communication Symposium [Proceedings online]; 2002 Mai 02-03. São Paulo, Brasil; 2002 [citado 2008 Jun 20]. Disponivel em: http:// w w w. p r o c e e d i n g s. s c i e l o.b r/ scielo.php? script $=$ sci_arttext\&pid $=$ MSC000000005 2002000100048\&lng=en\&nrm=.

21. Kenner C. Enfermagem neonatal. 2a. ed. Rio de Janeiro: Reichmann \& Affonso Editores; 2000. p. 121.

22. Nakano AMS. As vivências da amamentação para um grupo de mulheres: nos limites de ser "o corpo para o filho" e de ser "o corpo para si”. Cad Saúde Pública = Rep Public Health. 2003;19(Supl 2):355-63.

23. Nakano AMS, Reis MCG, Pereira MJB, Gomes FA. O espaço social das mulheres e a referência para o cuidado na prática da amamentação. Rev Latinoam Enferm. 2007;15(2):230-8. 